\title{
Integration of Leprosy Control into the Health Centre Scheme*
}

\author{
K. F. SCHALLER \\ Formerly Chief Medical Adviser in Leprosy to the Government of Ethiopia†
}

\section{INTRODUCTION}

In the last 100 years 2 outstanding events inspired the interest of the medical world in leprosy: the identification by Armauer Hansen in 1874 of the Mycobacterium leprae as the aetiological agent of the disease, and the discovery by Faget in 1941 of the action of the sulphones on the infecting mycobacterium. After Hansen's discovery physicians of international reputation from all over the world became interested in the pathology of leprosy, this increasing interest culminating in the First International Leprosy Congress, which was held in Berlin in 1897. Up to the introduction of the sulphones charitable organizations had predominated in leprosy work, but after their introduction leprosy became a curable disease and medical as well as public health schools included leprosy in their field of activities to an increasing extent. This change of attitude has without doubt been accelerated by the decision, exactly 20 years ago, of the World Health Organization (WHO) to include leprosy in its aid programme.

\section{MATERIALS AND METHODS}

Bechelli and Martinez Dominguez (1966) gave an idea of the magnitude of the leprosy problem in the world. They estimated that more than 2000 million people are living in areas with a prevalence rate of at least 0.5 per 1000 and may eventually be at risk of infection (Table 1). According to WHO estimates the number of new leprosy patients during the next 5 years is

* Received for publication 10 August, 1969.

†Present address: 2 Hamburg 52, Parkstrasse 54, Germany. expected to be approximately 1 million. It is further estimated that of the total number of patients in the world (more than 10 million) less than one-fifth have so far received any treatment.

Most of the countries with a high leprosy prevalence are located in the tropics or subtropics (Fig. 1). Economically considered, they are classified as "developing" countries, that is, countries characterized by a low gross national product, an inadequate infrastructure, slow growth of productivity with an economy mainly based on agriculture, uneven distribution of property, and a very high proportion of the population living in rural areas.

In the health sector the predominating features are infectious diseases, nutritional deficiencies, and high infant mortality rates. The limited health services are mainly of the curative type, with a concentration of physicians and hospitals in the capital cities and larger towns. In the rural areas the patient-

TABLE 1

Leprosy prevalence throughout the world according to WHO estimates in 1966 (Bechelli and Martinez Dominguez)

\begin{tabular}{|c|c|c|c|c|c|}
\hline $\begin{array}{c}\text { Estimated } \\
\text { leprosy } \\
\text { (rate per } 1000)\end{array}$ & Africa & $\begin{array}{r}\text { No. of } \\
\text { America }\end{array}$ & $\begin{array}{l}\text { countr } \\
\text { Asia }\end{array}$ & $\begin{array}{l}\text { ries in: } \\
\text { Europe }\end{array}$ & Oceania \\
\hline Less than 0.5 & 1 & 17 & 13 & 13 & 2 \\
\hline $0.5-0.9$ & 1 & 9 & 7 & 1 & 0 \\
\hline $1.0-4.9$ & 19 & 16 & 15 & 1 & 4 \\
\hline $5.0-9.9$ & 7 & 2 & 10 & 0 & 3 \\
\hline $10.0-19.9$ & 9 & 3 & 0 & 0 & 6 \\
\hline $20.0-29.9$ & 4 & () & 1 & () & 3 \\
\hline $30.0-39.9$ & 7 & () & 0 & 0 & 0 \\
\hline $40.0-49.9$ & 6 & & 0 & 0 & 0 \\
\hline More than 50.0 & 2 & & 0 & 0 & 2 \\
\hline
\end{tabular}




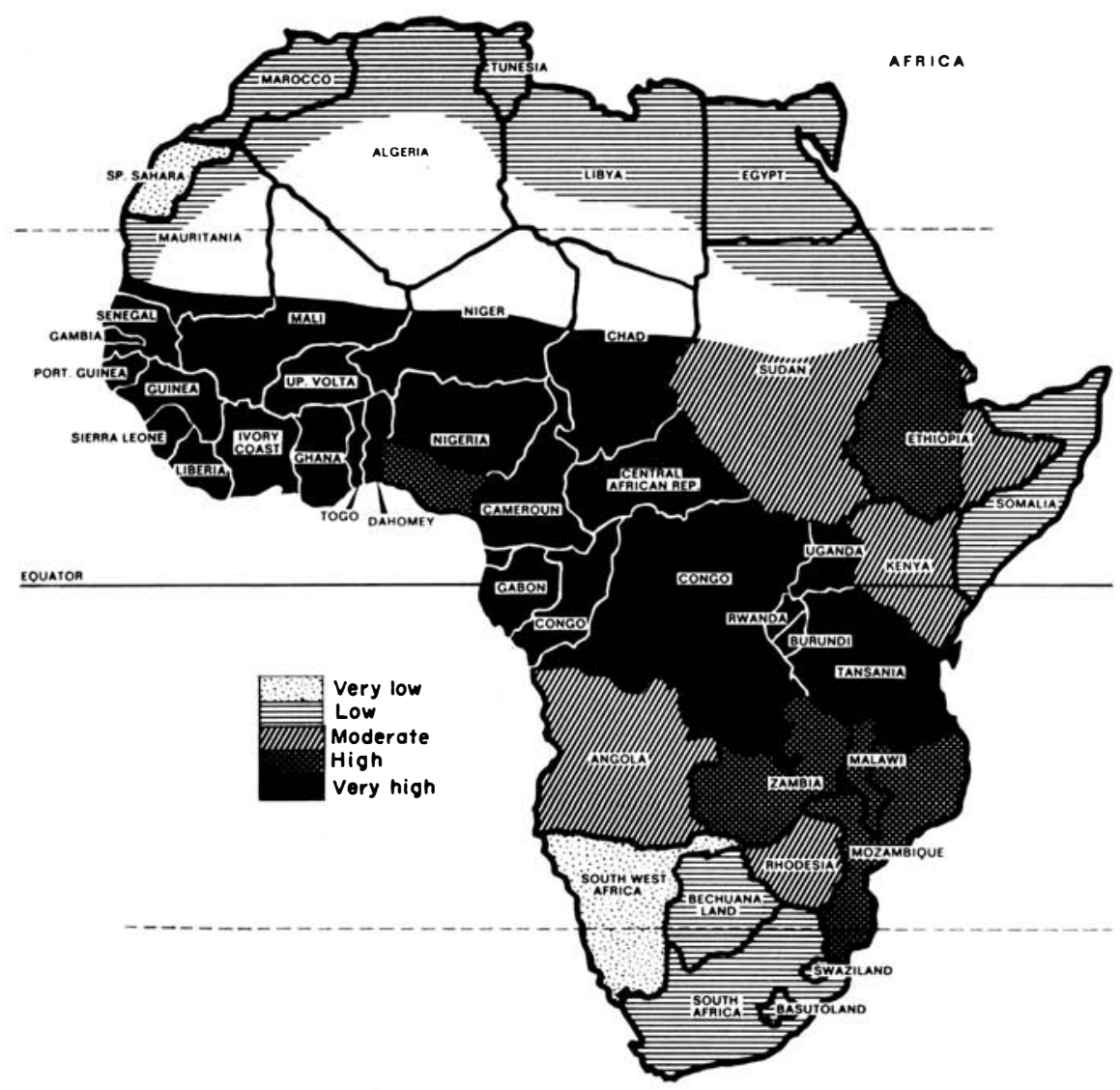

Fig. 1

Leprosy prevalence in Africa.

doctor rate ranges from 10,000 up to 500,000 patients per physician, particularly in Africa, and the relatively small number of hospital beds are available for only a minority of patients (Table 2). The population growth rates are around $2 \%$, with a life expectancy of only 35 to 40 years, but even less than 30 in some African countries.

Being aware that the vicious circle of diseasepoverty-fatalism-loss of productivity-increasing poverty-leading to more sickness, must be broken, the governments of these countries began to recognize that health is an integral part of their economic and social development.
TABLE 2

Ratio of physicians to number of inhabitants in various countries of the world (1964-66)

\begin{tabular}{crrrrr}
\hline $\begin{array}{c}\text { Physician } \\
\text { rate per } \\
\text { population }\end{array}$ & Africa & America & Asia & Europe Oceania \\
Less than 1000 & 0 & 2 & 2 & 15 & 3 \\
Up to 2500 & 3 & 10 & 6 & 5 & 4 \\
5000 & 8 & 11 & 6 & 0 & 2 \\
10,000 & 7 & 5 & 5 & 0 & 1 \\
20,000 & 12 & 2 & 3 & 0 & 1 \\
40,000 & 11 & 0 & 4 & 0 & 0 \\
60,000 & 2 & 0 & 1 & 0 & 0 \\
More than & & & & & \\
60,000 & 4 & 0 & 0 & 0 & 0 \\
inhabitants & & & & & \\
\hline
\end{tabular}


In their over-all planning for economic and social progress most of the developing nations are now giving adequate consideration to public health, their goal being to eradicate disease, poverty, and illiteracy. The guiding principle of their planning is the provision of the highest possible degree of well-being and health to the maximum number of people at the lowest possible cost.

The limitation of financial, technical and personnel resources is the decisive factor in the type of service to be applied. The maximum budget earmarked for health in developing countries lies around $15 \%$ of the total revenue, and ranges from 25 cents (U.S.) up to 4 dollars (U.S.) per head per year (Table 3). Nationalized health services have proved to be the most feasible solution in the majority of African and Asian countries, because they allow the main emphasis to be placed on the preventive aspects of medical care. In the organization of public health services the rural health centre has become the basic institution for the implementation of the various health programmes. In most instances, planning provides for a capillary network of health centres evenly distributed throughout the country. The size of population to be cared for varies between 20,000 and 80,000 individuals, depending on density, local

TABLE 3

Percentage of national budgets allotted to public health in some industrialized and developing countries with nationalized health services (1962-66)

\begin{tabular}{lr}
\hline \multicolumn{1}{c}{ Country } & Percentage of budget \\
\hline Congo (Brazzaville) & 18.0 \\
Dahomey & 15.0 \\
Togo & 14.0 \\
Great Britain & 13.0 \\
Bolivia & 11.2 \\
Japan & 10.5 \\
Sierra Leone & 7.8 \\
Soviet Union & 6.6 \\
Ethiopia & 5.7 \\
Iraq & 5.6 \\
Brazil & 5.1 \\
Indonesia & 5.0 \\
Turkey & 5.0 \\
India & 4.6 \\
Laos & 2.5 \\
\hline
\end{tabular}

needs, communication system and geographical structure. The activities of the health centres include: control of communicable diseases (often with priority for malaria), maternal and child welfare, environmental sanitation, health education, medical care, with some laboratory facilities, collection of vital statistics, and, to an increasing extent and mainly in Asian countries, family planning.

The gap between planning and realization of such essential health services necessitates the training and employment of larger numbers of auxiliary personnel able to take over tasks generally reserved for physicians. Most of the countries give preference to the "polyvalent" health worker. The few physicians available in rural areas have to devote most, if not all, of their time to tasks of training, supervising and planning. Subcentres or health stations in varying numbers-a rate of at least 5000 persons per health station is desirable-are attached to the health centres. The required buildings are preferably constructed in local style and material in order to achieve maximum cost-effectiveness (Figs 2 to 4 ).

The health centre is usually operated by a team, with a health officer in charge and assisted by community nurses, midwives, sanitarians, laboratory technicians, health educators, dressers, and clerks in varying numbers. The health stations are run mainly by nurses or dressers, all of whom have received their education within the country and are trained for, and on, the job, being supervised by workers of a higher level, generally the district or provincial officer of health.

If $i d e a l$ conditions exist, leprosy is adequately taken care of by the health-centre scheme. According to the needs, clinic hours for special diseases such as leprosy, venereal diseases, tuberculosis, or yaws can be arranged and held at regular intervals. Home visiting, case finding, surveys, treatment follow-up, examination of contacts, correction of insanitary conditions, health education of the public, and other measures can most easily be effected through a properly functioning health centre organization, 


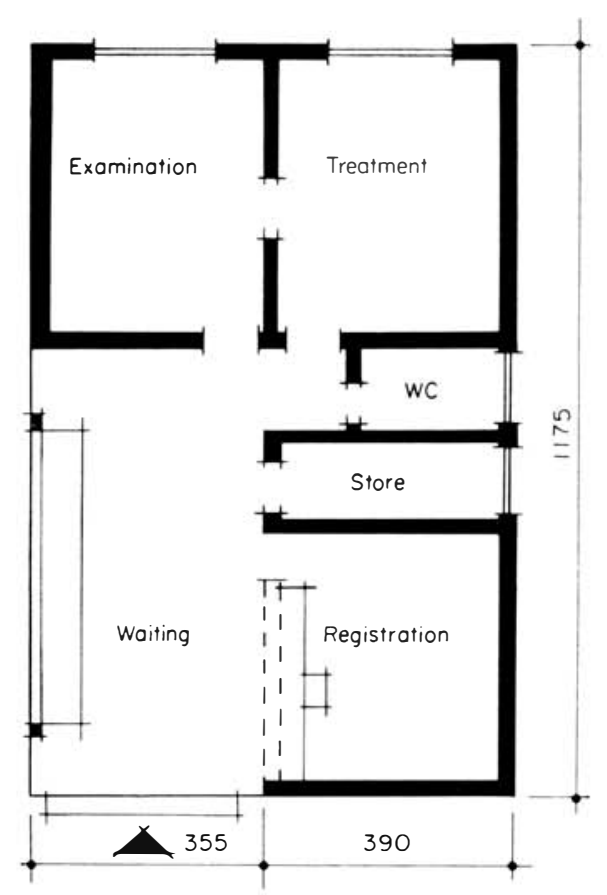

Fig. 2

Floor plan of a health station.

benefiting the whole population including, of course, leprosy patients.

In the majority of countries with a leprosy problem, control measures were initiated before health centres came into existence. Specialized services, often in close co-operation with missions or private institutions, have been in charge of leprosy control. Here the trend is directed toward gradual integration of leprosy services into the health centre scheme as far as out-patient treatment is concerned. At the end of this development the health centres could become the main institutions for the implementation of leprosy control activities.

The specialized leprosy services continue to exist at the ministerial level, their main objectives being:

(1) preparation of a plan of operations for the control and eventual eradication of leprosy;

(2) integration of the leprosy control programme into the scheme of basic health services;
(3) co-ordination and supervision of all governmental and non-governmental activities in the field of leprosy control;

(4) promotion of a rehabilitation programme;

(5) training of medical personnel at all levels in leprosy work;

(6) advising hospitals, clinics, health centres and other institutions on current leprosy problems;

(7) enlightenment of the public on the nature of the disease and its prevention;

(8) collection of as much information as possible on the incidence and spreading of the disease, as well as on social and other factors promoting and contributing to its spread; and finally

(9) maintenance of an effective reporting and notification system.

The operation of one or more demonstration centres with the aims of training personnel and 


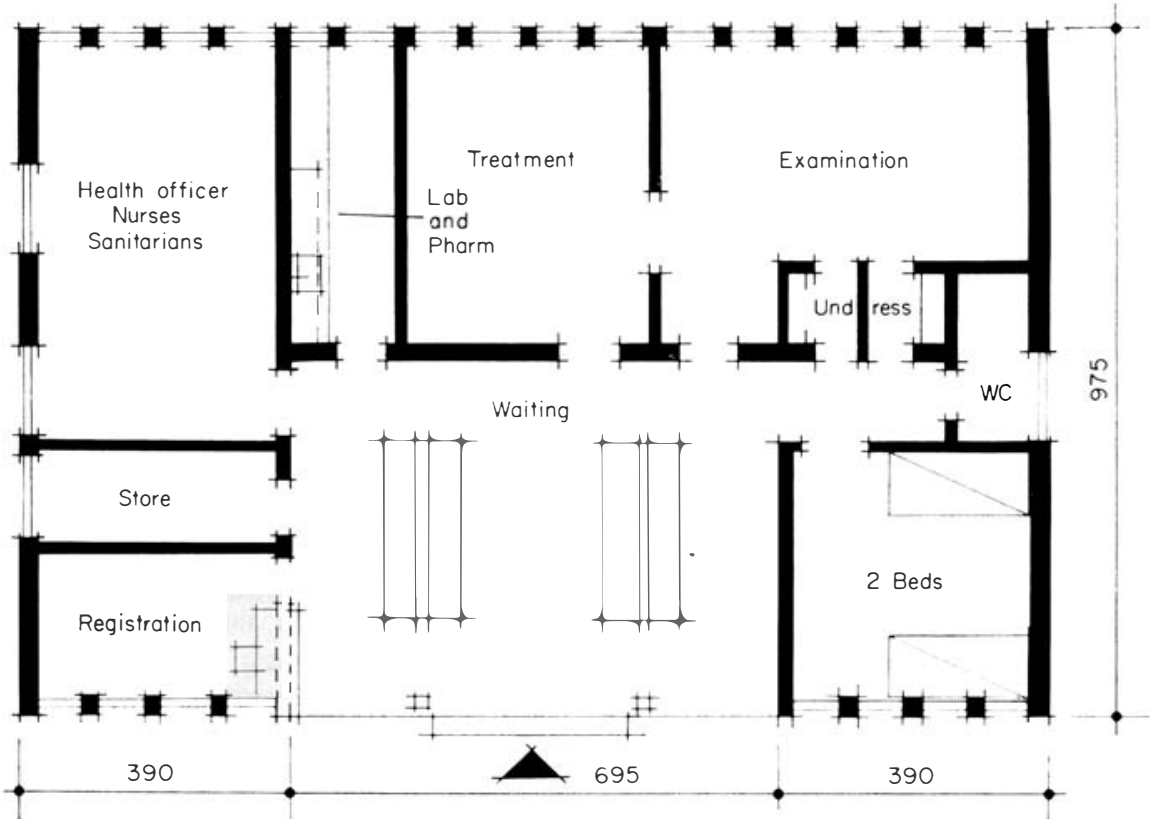

FIG. 3

Floor plan of a minor health centre.

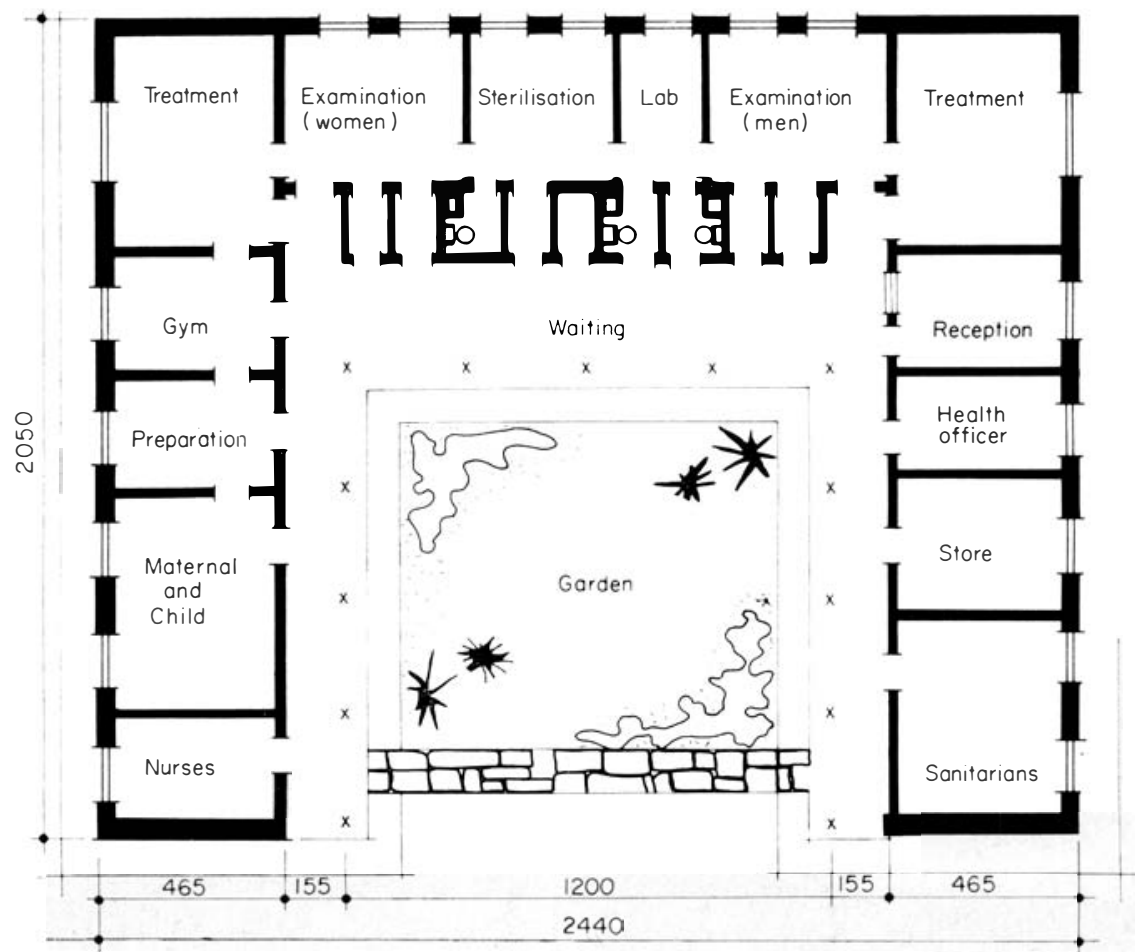

FIG. 4

Floor plan of a major health centre. 
forming a cadre of leprosy workers, introducing modern methods of diagnosis and treatment, and performing research in the field of leprosy has proved to be of the greatest value for the implementation of the control programme.

It is up to the chief of the leprosy control services to see to it that leprosy receives fair and just consideration within the health planning of the country, taking into account the chronicity of the disease, the number of persons involved, the social stigma and prejudices associated with it, the problem of rehabilitation, and other factors of importance. The guiding principle in leprosy control must be: early cure is the best prevention!

\section{SUMMARY}

Three significant developments make the expansion of leprosy control possible: the introduction of the sulphones; the importance given to out-patient treatment in combating leprosy; and the integration of leprosy control activities into the basic health-centre scheme. Special efforts should be made to harmonize general planning with new developments in the expansion of rural health services and the integration of the specialized services, such as leprosy control, into the scheme of the general health services.

It is indispensable to balance the planned expansion of the health services with the financial potential of the country and its capacity for training public health personnel.

\section{REFERENCES}

BeChelli, L. M. and MARTiNez DOMinguez, v. (1966). The leprosy problem in the world. Bull. Wld Hlth Org. 34, 811 .

SCHALler, K. F. (1965). Planung von Gesundheitsdiensten in Enwicllungsländern. Wien. med. Wschr. $11533 / 34,668$.

SCHALLER, K. F. (1969). Die geographische Verbreitung der Lepra in Entwicklungsländern. Z. Tropenmed. Parasit. 20, 1, 10 .

SCHALLER, K. F., TIEDEMANN, E. and ERNERT, E. W. (1964). Public health in Ethiopia. Second five-year development plan 1963-67, Addis Ababa.

WORLD HEALTh ORganization. Technical Report Series No. 83 (1954). Methodology of planning an integrated health programme for rural areas, Genevs.

WORLD HEALTH ORGanization. Technical Report Series No. 215 (1961). Planning of Public Health Services, Geneva.

WORLD HEALTh ORGANization. Epidemiological and Vital Statistics Reports, 1964-68, Geneva. 